\title{
Molinos hidráulicos de la zona oriental de Cantabria
}

\author{
Miguel Cisneros Cunchillos, Pilar lópez Noriega \\ y Rafael Palacio Ramos \\ Universidad de Cantabria
}

\section{INTRODUCCIÓN: EL ORIGEN DEL MOLINO HIDRÁULICO ${ }^{1}$}

El origen del molino va ligado a la necesidad del hombre de triturar las partes duras de los alimentos cultivados. La primera solución técnica a este problema fue el molino de mano, el cual en su origen se componía de una piedra inferior fija y otra superior, móvil y de menor tamaño, con la que se machacaba el grano.

El correr del tiempo llevó a nuevas soluciones tecnológicas que dieron lugar, en un primer momento, a los molinos de sangre -que se accionaban por la fuerza humana, y cuando ésta era insuficiente, por la de los animales de tiro- y en un segundo momento, a aquéllos que aprovechaban los recursos naturales, como el agua o el aire, para su funcionamiento.

Se piensa que los molinos hidráulicos surgieron en el Próximo Oriente o en Asia Menor hacia el siglo I a.C. y que en ello influyeron los numerosos cursos de agua de la zona y, lógicamente, el conocimiento del mecanismo de molienda, que, aunque constatado en el VIII-VII milenio a.C., se remonta, posiblemente, a épocas prehistóricas. Sin embargo, su extensión debió acontecer entre los siglos III y xIv, documentándose en Inglaterra, Irlanda, Escandinavia y Francia. Es, precisamente, en la Edad Media cuando se documentan en España, marcando su apogeo en el siglo xII, debido al impulso árabe ${ }^{2}$. Por lo que respecta a Cantabria,

1 Este trabajo se enmarca en el proyecto de investigación "El Astillero de Colindres: recuperación arqueológica y documental de su actividad», que se desarrolló en las Áreas de Conocimiento de Arqueología y de Ingeniería de la Construcción de la Universidad de Cantabria y que financió el Excmo. Ayuntamiento de Colindres, en virtud del Convenio suscrito entre ambas instituciones, durante los años 1993 a 1996.

2 J. Escalera y A. Villegas, Molinos y panaderías tradicionales (Madrid, 1983), pp. $18-29$. 
su aparición documentada se produce en la comarca de Liébana, en el siglo $\mathrm{IX}^{3}$.

El molino hidráulico conoció una gran implantación en la Península Ibérica, extendiéndose su empleo en zonas de abundante caudal hídrico, como es la actual Comunidad Autónoma de Cantabria. Su funcionamiento es en esencia muy sencillo, ya que aprovecha el caudal del río embalsado para mover una o varias ruedas de molienda. Lógicamente, en los cauces poco caudalosos los períodos de actividad se restringían a las estaciones lluviosas o de deshielo. Por lo que respecta a su tipología, existen dos modelos fundamentales: el de "puente", en el que las aguas discurren bajo la edificación, y el que contempla el paso del caudal por un costado; el primero precisa una sólida construcción a base de sillares capaces de soportar el flujo del agua y su rueda es forzosamente vertical: es este el tipo más común en los molinos de río cántabros ${ }^{4}$.

El molino de marea, variante del hidráulico, utiliza el flujo y reflujo de la marea como energía; aprovecha la pleamar para llenar su depósito y, una vez producido este hecho, sólo queda esperar a la bajamar para efectuar la molienda. La escasa amplitud de las mareas del Mediterráneo lleva a pensar que evidentemente su origen esté ligado al Océano Atlántico o al Mar del Norte 5 . Los primeros molinos de marea conocidos aparecieron en Bayona, las costas de Bretaña y Venecia. Desde aquí, probablemente, comenzó su expansión hacia el Sur hasta alcanzar las costas de Portugal; de cualquier modo, las primeras referencias documentales de molinos de marea en Cantabria son ya del siglo XI, ubicándose en las villas de Argoños y Escalante, pertenecientes a las marismas de Santoña ${ }^{6}$, y en el xv ya existen abundantes referencias a toda la costa regional.

En el presente trabajo se realiza una aproximación a los molinos hidráulicos de tres municipios del Oriente de Cantabria: los molinos de río de la localidad de Castillo Siete Villas y los de marea de los municipios de Colindres (fig. 1), como ejemplo del aprovechamiento exhaustivo de los recursos naturales de cada área, al tiempo que se ofrece una relación de cada uno de estos ingenios y su estado actual de conservación.

3 M. E. Álvarez LlopIS, "Molinos hidráulicos en Cantabria, siglos x al XIII", VV.AA., El Fuero de Santander y su época (Santander, 1989), p. 413.

4 J. M. Malo Mateo, s.v. "Molino (Arquitectura)", VV.AA., Gran Enciclopedia de Cantabria (Santander, 1985), tomo V, p.272.

5 B. As López, "Muiños de marés da ría de Arousa", Brigantium 2 (1981), p.143.

6 M. E. Álvarez Llopis, op. cit., n. 3, p. 413. 


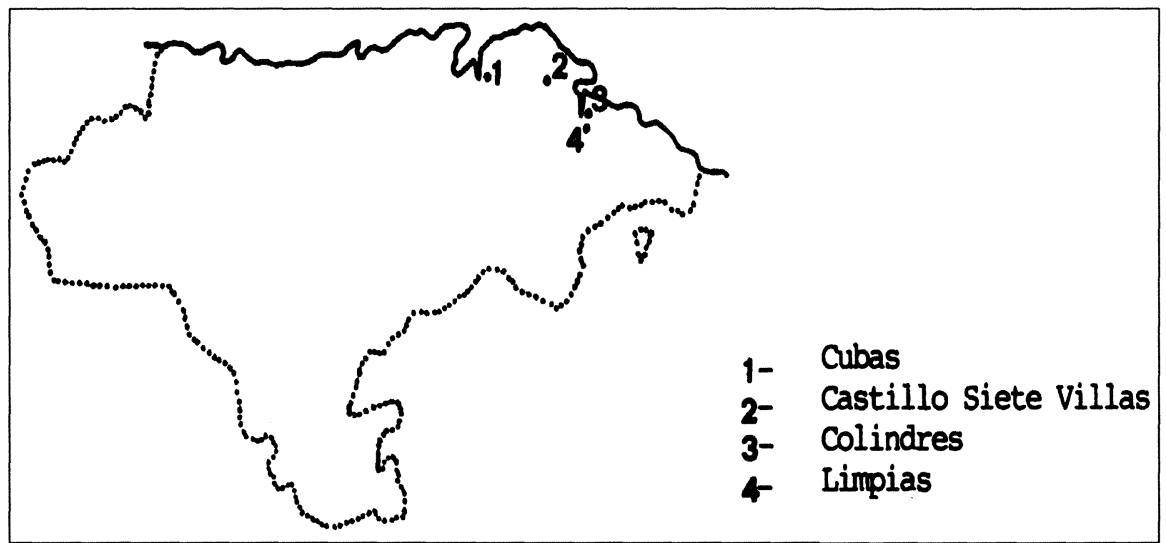

Figura 1.-Mapa de ubicación de las localidades de Cubas, Castillo Siete Villas, Colindres y Limpias.

\section{BREVE RESEÑA DEL MARCO HISTÓRICO}

En lo que se refiere a Cantabria el auge de los molinos hidráulicos, de río y marea, se centra en los siglos XVII y XVIII, coincidiendo con unos acontecimientos históricos que facilitan su expansión, pero serán la causa de su posterior declive.

En el siglo XVII, Cantabria se enfrenta a una importante recesión económica que se intentará paliar con la utilización intensiva de los recursos productivos, mediante la reorganización del espacio agrícola y ganadero. Se introduce el maíz y su expansión será tal que llegará a convertirse en el cultivo dominante de un sistema de roturación bienal. A manera de ejemplo, se puede comentar que la cosecha de cereales en Colindres y Limpias fue ocho veces mayor a mediados del siglo xviI que lo que había sido a comienzos del XVII ${ }^{7}$.

Por otro lado, en el siglo XVII continúa para este territorio la fragmentación jurisdiccional y administrativa dominante en las centurias anteriores, en las que la Iglesia, la nobleza y otras entidades jurídicas que se pueden denominar "inferiores", pero que tienen un enorme peso e independencia, los Concejos, siguen siendo autónomos del poder monárquico; así subsiste una propiedad basada en mayorazgos y obras pías, en la que se es consciente de que en caso de necesidad siempre se puede recurrir a los recursos americanos. Ello provocó un retraso con respecto a Europa

7 R. LANZA, La población y el crecimiento económico de Cantabria en el Antiguo Régimen (Madrid, 1993), pp. 158-167. 
del que se pretende salir en dicho siglo ${ }^{8}$. En Cantabria, este intento de modernización aprovecha la importancia de la actividad naval, primero en Colindres, durante el s. XVII, y después en Guarnizo, en el XVIII ${ }^{\text {; }}$ así, surgen las fábricas de Liérganes y La Cavada, que suministran cañones y piezas de hierro, en general, para barcos y baterías costeras de defensa. Tal actividad acabó provocando la desforestación de las áreas limítrofes, dada la gran cantidad de carbón vegetal que se empleaba en dichas ferrerías ${ }^{10}$.

Otro elemento interesante a tener en cuenta en este proceso es la red viaria. A mediados del siglo XviII se terminará el camino de Reinosa a Santander, que permitirá el tráfico de mercancías desde el interior hasta la costa, en unas fechas en las que, además, se inician las obras del Canal de Castilla ${ }^{11}$. Ahora bien, el camino de Castilla está documentado desde 1590, momento en el que se conoce la reparación del puente de Solía, la reconstrucción del de Arenas de Iguña y la construcción de los de Puente Arce y Santiago de Cartes; una vez en Reinosa, el camino se bifurcaba bien hacia Burgos, por Reocín de los Molinos, o hacia Palencia, por Aguilar de Campoo ${ }^{12}$. A partir del siglo XVI y a lo largo del XVII, la región tuvo una tupida trama viaria que permitía el transporte en todas direcciones, de la que son testigos los numerosos puentes y restos de caminos y a la que no fue ajena la importante industria de fundición ${ }^{13}$.

Sin embargo, y a pesar de contar con una base propicia para ese proceso modernizador, éste no aconteció, tampoco en el siglo xVIII, porque en Cantabria el hecho colectivo tuvo más importancia que la actividad económica privada; esta desprivatización afecta a la propiedad en general y se manifiesta, como ya se ha comentado, de forma particular en la agricultura. Este marco afectó también a la industria, en la que, como ha señalado J. Maiso, no existían las relaciones impersonales entre patrón

8 J. MAISO, "La sociedad de Cantabria y el Astillero ante la modernización en el siglo XVIII, VV.AA., Actividad constructora naval y nuicleos de población en torno a la Real Fábrica de Bajeles del Astillero de Guarnizo (Astillero, Cantabria, 1991), pp. 94-95.

9 M. Cisneros, R. Palacio y J. Castanedo, El astillero de Colindres (Cantabria) en la época de los Austrias Menores. Arqueología y construcción naval (Santander, 1997) y J. Castanedo, Guarnizo, un astillero de la Corona (Madrid, 1993).

10 R. PAlacio Ramos, "Transformación y comercio del hierro en la Bahía de Santoña y el río Asón", VV.AA., Hierro al mar. Litoral atlántico, 2 (1999), pp. 144-151.

11 J. MAISO, op. cit. n. 8, p. 98.

12 M. A. Aramburu-Zabala y B. Alonso Ruiz, Santander: un puerto para el Renacimiento (Santander, 1994), p. 129.

13 M. A. Aramburu-Zabala y B. Alonso Ruiz, op. cit. n. 12, p. 133 y M. Cisneros y P. López NORIEGA, "Vías romanas o caminos antiguos en el sector central de la Cordillera Cantábrica”, XXIII Congreso Nacional de Arqueología, II (Elche, 1995), p. 64. 
y obrero, sino que "los trabajadores se sentían ligados por lazos afectivos y de fidelidad a la casa y a la sucesión dinástica de ella " ${ }^{14}$. Es decir, había una actitud paternalista y de control, más que una racionalización económica con vistas al beneficio.

En este ambiente se incluyen los principales molinos de Cantabria, aprovechando el intenso comercio de productos agrícolas que, junto a otras producciones, se llevan, sobre todo, al puerto de Santander, que se convertirá en uno de los puntos de embarque más importantes del mar Cantábrico ${ }^{15}$

A lo largo del siglo XIX, tendrá lugar su declive, en el que influirán la reducción de la actividad de los astilleros - la importante construcción naval de Guarnizo, durante el xvIII, será trasladada a El Ferrol-, la instalación de molinos harineros en Castilla y la transformación de los medios de transporte -aparición del ferrocarril-, entre otros factores ${ }^{16}$.

Respecto al estado de la investigación en Cantabria sobre los molinos de marea, y como sucede en otros muchos testimonios ligados a la Arqueología del mar - asentamientos humanos, astilleros de ribera, faros, puertos y fondeaderos, fortificaciones costeras, garitas de vigía, etc.-, se encuentran numerosas referencias bibliográficas, lo que en apariencia muestra un estadio avanzado de la investigación, cuando lo cierto es que aún no existe el suficiente trabajo de archivo y de campo que permita contar con un inventario fiable y completo. Habiendo trabajos parciales en otras comarcas ${ }^{17}$, sólo ha sido estudiada en cierta profundidad la oriental: en Siete Villas los molinos de las rías de La Venera y Quejo y el complejo marismeño de Victoria y Joyel, y en la Bahía de Santoña recientemente los de Escalante y de la propia Santoña ${ }^{18}$.

14 J. MAISO, op. cit. n. 8, p. 103.

15 L. Azurmendi, Molinos de mar (Santander, 1985), p. 21.

16 L. AZURMENDI, op. cit. n. 15, p. 33.

17 J. Marcos Martínez, "Molinos de marea en la Bahía de Santander: el ingenio de Perojo (Muriedas, Camargo, Cantabria)", Trabajos de Arqueología en Cantabria, III (1996), pp. 125-144.

18 Hay que destacar de manera especial el exhaustivo trabajo de L. DE Escallada GonzÁlez, "Molinos de mareas de Siete Villas", Anuario del Instituto de Estudios Marítimos "Juan de la Cosa", 6 (1988), en el que se ofrecen datos y documentos de los siglos XVI a XIX. En cuanto a la recuperación de los molinos de marea de VictoriaJoyel, véase L. Azurmendi, op. cit. n.15 y "Conservación de molinos de mar en Trasmiera", Cuadernos de Trasmiera, I (1988). Respecto a la Bahía de Santoña, los molinos de marea y de río de Escalante se pueden consultar en M. A. AramburuZABALA y otros, Catálogo monumental del municipio de Escalante (Santander, 1997), pp. 83-87. Los de Santona han sido muy recientemente presentados por R. PALACIO 


\section{EL RÉGIMEN DE PROPIEDAD DE LOS MOLINOS}

Este aspecto de los molinos hidráulicos ha variado no poco desde la Edad Media hasta el siglo XIx. En aquélla eran propiedad de los señores feudales, las órdenes religiosas y militares y los monasterios. Este monopolio les proporcionaba una importante fuente de recursos y el control del abastecimiento de la población. Los titulares de estos derechos eran los únicos que podían construir molinos en sus posesiones y controlaban el transporte del grano y el uso del agua, obligando al campesino a pagar un canon, generalmente, una parte del grano o de la harina ${ }^{19}$.

Esta situación de privilegios y monopolios no parece haber evolucionado de manera importante hasta el XIX, avanzándose hacia una propiedad comunal del molino. Varios individuos se unían para su edificación, dado el coste que esto suponía. En este caso, el funcionamiento se regiría por un turno y horario, que debió producir frecuentes disputas y peleas, lo que fue abocando a la propiedad individual. De todas formas, al hablar de propiedad individual, se debe distinguir entre gran y pequeña propiedad. Parece claro que los molinos que reportaban mayores rentas, pertenecían a grandes propietarios. Su rentabilidad era tal que los notables mantuvieron su propiedad a lo largo del siglo xviII e incluso la incrementaron en las últimas décadas. Una realidad distinta la proporcionan aquellos molinos manejados directamente por sus propietarios, que tenían en ellos la única fuente de subsistencia. En este caso, el dueño es quien realiza el trabajo en el campo y el de la molienda, bien solo, bien ayudado por su familia ${ }^{20}$. Este tipo de propiedad decaerá a lo largo del s. XVIII, ya que un molino construido con reducido capital implicaría poca capacidad, y, por consiguiente, poca rentabilidad. De ahí que muchos propietarios se viesen obligados a venderlos o a hipotecarlos, pasando, lógicamente, a la gran propiedad ${ }^{21}$.

RAMOS, "Molinos de marea de la villa de Santoña", Actas de las II Jornadas Nacionales de Molinología, Tarrasa, 1998 (en prensa); este estudio ha sido realizado en el marco del proyecto de actuación arqueológica "Arqueología del mar en Santona: documentación de las estructuras y yacimientos de épocas moderna y contemporánea (DAM), dirigido por Rafael Palacio Ramos desde el año 1997 y que cuenta para su desarrollo con subvención de la Consejería de Cultura y Deporte del Gobierno de Cantabria.

19. J. Escalera y A. Villegas, op. cit., n. 2, pp. 34-37.

20 A. Limpo Llofriu y J. A. Sebastián MAESTRE, "Los molinos de agua y grano en Lugo", Narria, 63-64 (1993), p. 19.

21 A. M. GUTIÉRREZ, J. J. MUÑoz y S. ARIZTONDO, La industria molinera en Vizcaya en el siglo XVII (Bilbao, 1984), pp. 141-151. 
Cantabria ofrece fuertes divergencias con este panorama general. Ya para la Edad Media, debemos rechazar la idea de la existencia de un monopolio señorial, puesto que no existían otros impedimentos para la construcción de un molino por parte de cualquier persona que no fueran las limitaciones técnicas o económicas, nunca jurídicas ${ }^{22}$. En cuanto a la administración de los molinos, era común la fórmula del arrendamiento, entendiéndose el molino, bien como objeto único de arriendo, bien incluido en un conjunto de edificaciones y tierras. Las rentas que proporcionaban los molinos se efectuaban en especie o en dinero. En el primer caso, no solo se realizaba en grano, sino que también podía incluir otro tipo de productos agrícolas e incluso ganaderos. A la vez, se establecían para el inquilino una serie de obligaciones, posiblemente como reminiscencias de carácter feudal ${ }^{23}$.

En Cantabria, se conocen cuatro regímenes de propiedad para los molinos: 1) los vinculados a mayorazgos, 2) los que pertenecían a varios vecinos, que molían unos días al año y cuyo derecho podían vender y transmitir por herencia, 3) los pertenecientes a concejos y 4) los particulares $^{24}$. Un caso interesante, que completa el panorama ofrecido líneas arri$\mathrm{ba}$, lo encontramos en un molino de Castillo Siete Villas, propiedad de cuatro vecinos que no tienen en la agricultura su principal medio de vida; nobles todos ellos, dos eran campaneros, y uno cantero: artesanos que percibían el diezmo o maquila de aquéllos que utilizaran la aceña ${ }^{25}$.

Algunos de dichos regímenes de propiedad están documentados en el municipio de Colindres. En 1515, en el testamento de Sancho García de Mori se amanda que se digan dos misas rezadas cada semana en la dicha de su capilla y que se den por cada misa doce maravedís, hipotecando un cuarto de molino en el de la Torre, que hubo y heredó de sus padres y que le tenga su hijo mayor y sus sucesores para siempre jamás» ${ }^{26}$. En 1516, el molino de Cuesta de Mar fue vendido a Juan García de Mori. En 1534, Pedro García de Mori hace testamento y manda que las dos misas perpetuas a la semana las pague Juan de Mori, señor de la Casa de Mori,

22 M. E. Álvarez llopis, op. cit. n. 3, p. 421.

23 A. M. Gutiérrez, J. J. MuÑoz y S. ArizTONDO, op. cit., n. 21, pp. 151-166 y A. Martín, "Molinos hidraúlicos de la Rioja en el siglo XVIII", VV.AA., Los Molinos: Cultura y Tecnología (Madrid, 1988), pp. 199-201.

24 L. DE Escallada González, op. cit., n. 18, p. 206.

25 T. Maza Solano, Nobleza, Hidalguia, Profesiones y Oficios en la Montaña, según los Padrones del Catastro del Marqués de la Ensenada (Santander, 1957), tomo 3, pp. 992-999.

26 T. MAZA SOlano, Documentos del Archivo de las Casas Solariegas de Escalante y la Obra, en la Villa de Laredo, y de Mori, en Colindres (Santander, 1931), p. 17. 
y "manda que los molinos de Tintero sean de Mayorazgo" ${ }^{27}$. En 1614, Isabel de la Puebla arrienda a María del Río una rueda del molino de la Magdalena y a Juan González de Cossío el del barrio de Nadal, ambos por un período de cinco años. En 1616, Juan de Pereda Salazar alquila a María de la Serna una rueda del molino de la Cuesta de Mar. En 1636, Martín Antonio de Puerta y Riquelme poseía un molino en la Cuesta de Martín Mino. En 1652, la familia de Gil de la Redonda alquila el molino de marea de su propiedad por 16 reales de renta ${ }^{28}$. En 1675, se dio posesión a Luis del Hoyo Alvarado de diversos bienes por vínculo y mayorazgo, entre ellos estaba "un sitio de tres ruedas de molino de mar en el que se dice Falgote ${ }^{29}$.

\section{EL FUNCIONAMIENTO DEL MOLINO}

Ya se ha hecho referencia a dos tipos de estructuras hidráulicas: el molino de río y el de marea. La primera es más antigua que la segunda, como ya ha quedado dicho con anterioridad, pero ambas están movidas por la acción del agua; ahora bien, existen diferencias entre una y otra que se van a analizar a continuación.

El molino de río emplea unos muros para embalsar el agua, conformándose de este modo una azuda o represa de superficie y capacidad muy variables; su construcción debe ser cuidada o de buena factura para impedir pérdidas, dada su dependencia de un caudal concreto, por lo que a menudo se realiza con sillares o sillarejo bien escuadrado. A diferencia de éste, el molino de marea utiliza unos diques para cerrar la marisma, que es inundada con la pleamar; en este momento es cuando se cierran las compuertas de entrada del agua, que es dirigida hacia canalizaciones interiores. Sólo cuando el nivel del agua exterior ha bajado, es decir, en la bajamar, se abren los mecanismos del molino, que llevan el agua embalsada hacia los rodetes, aprovechando la fuerza producida por el salto de agua. La ventaja de esta estructura hidráulica frente a la citada en primer lugar es que, aunque sujeta a los ciclos mareales, no se veía afectada por los períodos de sequía ${ }^{30}$.

Los muros de embalse se llaman manguardias o estacadas. Sobre ellos se sitúa el edificio del molino. La entrada del agua, a modo de embudo,

27 T. MAZA SOlano, op. cit., n. 26, pp. 18 y 21.

28 M.` C. GONZÁlez ECHEgARAY, Colindres. Un enclave sobre el mar (Santander, 1990), pp. 92-93.

29 T. MAZA SOlanO, op. cit., n. 26, pp. 25-26.

30 L. De Escallada González, op. cit., n. 18, pp. 205-206. 
la dirige hacia unas compuertas, que permiten el llenado del embalse. La salida del cauce se produce bajo el edificio, tras haber pasado por conducciones estrechas que aumentan su velocidad, con objeto de producir la fuerza necesaria para que giren las ruedas hidráulicas; efectuado su paso por éstas, el agua sale por las arcadas que la estructura presenta en la fachada. El edificio del molino, propiamente dicho, ubicado en el piso superior, contiene la sala de máquinas, el almacén y, en algunos casos, la vivienda ${ }^{31}$.

Los molinos hidráulicos pueden ser de rueda horizontal o vertical; ésta es la empleada invariablemente en los de marea. La rueda recibe el nombre de rodezno o rodete y su movimiento se transmite al de la piedra corredera o volandera, a través de una serie de engranajes ${ }^{32}$. Una descripción detallada de su funcionamiento la expone L. Azurmendi, a partir de la descripción efectuada por los últimos molineros de Rada:

El flujo del agua acelerado en los abocinamientos se proyecta a través del saetillo sobre las aspas de la rueda horizontal, el rodete, que hace girar un eje vertical de madera, la cual culmina en una pieza metálica, la espada, donde se introduce la neja que se acopla a su vez en la campana de la piedra superior o volandera que gira y fricciona la piedra inferior o solera, que permanece fija. La volandera dispone en su centro de un seno por donde se introduce el grano almacenado en la tolva y que tras la fricción sale por las canaletas a los recipientes de recogida. Las piedras de molienda tienen, en su cara común, unas hendiduras radiales, que permiten la salida del grano ya triturado; la superficie de contacto no es homogénea y tiene diferentes zonas de apoyo y funciones que son el cascante, el moliente y el afinante. El eje vertical de madera gira, apoyado en su parte inferior sobre una pieza metálica, el quicio que a su vez descansa sobre una viga horizontal que, apoyada en un extremo y suspendida de una varilla en el otro, permite, al accionar ésta desde la sala de máquinas, conseguir diferentes presiones entre las piedras y por lo tanto diferentes grados y tipos de molienda. Son elementos complementarios el dispositivo que regulaba el flujo de agua en el saetillo, la çaja o tambor que encierra la volandera y un sonijete que regula la cantidad de grano de la tolva. Las operaciones de montaje de la volandera se realizan a través de la cabia que con un par de tenazas levantaba la piedra ${ }^{33}$.

\section{CONTRATO DE CONSTRUCCIÓN DE UN MOLINO DE MAREA, DE 1703}

En el Archivo Histórico Provincial de Cantabria ${ }^{34}$ se conserva un interesante documento, que nos ilustra acerca de los métodos constructivos

\footnotetext{
31 L. AZURMENDI, op. cit., n. 15, pp. 25-27.

32 J. Escalera y A. Villegas, op. cit., n. 2, p. 70.

33 L. AZURMENDI, op. cit., n. 15, pp. 28-29.

34 AHPC, Sección Protocolos Notariales, leg. 4966, ff. 45-48.
} 
utilizados para un molino de marea en los albores del siglo XviII. Se trata del contrato de construcción de una aceña sobre el arroyo de Villalante, afluente de la Ría de Cubas que vierte sus aguas en la Bahía de Santander.

El contrato se firmó el 13 de junio de 1703 entre Manuel de Cevallos Castanedo, vecino de Cubas, y los maestros canteros Francisco de Hontañón, Bernardo de Jorganes y Francisco del Corro, vecinos del lugar próximo de Gajano. Tenía por objeto ajustar la construcción “...del molino que el dicho Don Manuel pretende hazer cercano assucassa en el Rio de Villalante. El valor del trabajo alcanzaba los 1.200 reales de vellón, cuyo pago se efectuaría en tres partes iguales, la primera antes de comenzar "para prevencion de materiales, y plantar la obra", la segunda "ael medio de la obra", y la última "en acavando toda la dicha obra en toda perfecion a bista de maestros peritos en el arten.

El documento, que se complementa con un valioso plano de un molino de marea, similar al que se pretendía levantar (fig. 2), no se detiene por desgracia en los aspectos relativos al dispositivo para moler el grano, quedando al cargo de los canteros "...todo lo que fuere nezesario como es el rodete nuebo sus manillas, y verros, soleras, sobre que se ha de asentar dicho rodete..."

Sin embargo, sí se describen minuciosamente las trazas, materiales y técnicas, por lo que procedemos a transcribir la parte correspondiente:



FIGURA 2.-Traza y condiziones del molinito ronchon del patronato capellania laycal de d genaro de cevallos ala puerta de su casa en el varrio de las varcenas, 1703 (Archivo Histórico Provincial de Cantabria). 
La Prinzipal que lapersona de cuyo cargo este lareferida fabrica aya de Abrir un zimiento deoriente a oczidente con la longitud y latitud que demuestra la planta con suprofundidad nezesaria para su firmeza sobre tierra virgen opeña y estando en la conformidad referida bien limpia y anivelada la dicha planta se reinchira con buena argamasa y mezcla de cal y arena echandole dos palas de cal a tres de arena de la bega de la mexor que se alle y porque esta reconocido que en la dicha planta seallaran algunas guareñas se buscara entre una yotra peña latierra ariva menzionada y estos guios como ba dicho se reinchiran de ripio menudo y cal asta anibelar con las superfizies de las peñas y el cortezo de la parte baxa se ara de manposteria la mas crezida que se pueda y el de la parte de la agua anibeladas dichas guareñas seexecutara de silleria asta la comporta y mobimiento de Angulo y a dicho nibel se dexara porla parte baxa un rodapie o zapata dexando el grueso del paredon en seis pies de bien cumplidos yten que el setino aya deser todos sus cortezos de piedra de silleria labrada apicon bien escuadrada delas canteras del lugar de Cubas y dicho setino secabara la salida de agua en dos piezas dexando suentrada y salida del agua en la forma demostrada en la dicha planta como tambien se plantaran las paredes de la casa al mismo tiempo que dicho paredon y el setino se elixira su salida mas alto del superfizie del agua contoda con la madera que sea y atravesar en la salida del agua según que tambien esta demostrada con la disminuzion y quepor la parte de ariva se elixira el alto de quatro pies contados desde la superfizie de la referida agua y suentrada como esta demostrada yel alto de dos pies y medio y en todos los sillares y pieza del dicho setino en sus lechos enbocaduras para la mechas del batan y tanbien en cada una de las juntas.

Yten que la comporta seaya de elixir al nibel de la eleczion del dicho setino por la parte de ariva y que porque mexor guarde el agua seaya de azer envirado por todos lados de figura quadrilatera para quecon un sillarito bien enbetunado sepueda tapar sin quebazie gota la dicha comporta y que quando sea de abrir con una botabara seleaga botar fuera y sean de bolver a embetunar y poner como antes.

Yten que todo el dicho paredon aya delebantar desde el superfizie referido del agua baxa qeoy corre por dicho sitio ocho pies sin la profundidad de la planta y todo bien executado de mamposteria gruesa sus cortezos menos lo que demuestra la planta dela parte de ozidente asta la comporta que comoba dicho a de ser de sillares despues de anibeladas sus guareñas queasta tanto a de ser mazizado de ormigon que sedize ripio menudo y buena mezcla de cal y arena como todo el miaxon del dicho paredon en dicha forma y la puerta del dicho molino ade ser de piedra labrada con sus tranqueros y la planta y alzado con los altos nezesarios para que las personas puedan entrar libremente con las cargas por la menzionada puerta y tambien dentro las puedan manexar sus treze paradillas de canteria .Y laparte dabaxo su madera con sus enplastones y tabiques cabrios lata texa y todos los demas materiales y rodezno salvo las muelas por quenta de cuyo cargo tomara su execucion con su armadura que llamamos molinera y asimismo escondizion que las personas que tomaren asu cargo la fabrica dedicho molino handeser obligados alimpiar la presa entodo lo que fuere necesario de longitud latitud y profundidad dexando el suelo de dicha presa 
una quarta mas baxo quela solera de dicho saetino y la tierra que de dicha presa saliere seha de sacar fuera debaxo de los castaños de Dn Antonio de la Aza, demanera, que quede desbiado del terreno de dicha presa porquenose desmorone dicho terreno y echo y limpia que sea dicha presa se abriran los cimientos del paredon de dicho molino en la conformidad arriba dicha adbirtiendo que la silleria y mortero delaparte del agua sea de plantar dos pies y medio mas abaxo quela solera de dicho molino masmenos lo que combiniere y fuere nezesario y desde alli hadecorrer dicha silleria anibel por todo el largo de dicho paredon, y en la parte, que lo separe peña sea de rozar para que la silleria quede encaxada enella y en relazion a las guareñas que hubiere entrepeña y peña se han de calar con una palanqueta sacandoles el cascaxo o tierra que tubieren y hecho semazizaran con buen ormigon de cal y ripio y el cortezo de la parte de abaxo que hubiere entre peña y peña sea de fabricar con man posteria la mas crecida que hubiere, y dicho paredon ade tener de largo setenta pies debara que hacen diez tapias reales, y dealto loque fuere nezesario en la conformidad que arriba ba dicho y tambien es condizion queel cortezo dedicha silleria por la parte dedicha presa ha detener de largo asta la tronera de la comporta, y mas dicha comporta y su acompanamiento de parte deel cotornal, y lo restante de dicho paredon ha deser de mamposteria de cinco pies degrueso, con el largo, y alto arriba dicho demanera, que dicho paredon hadeser fabricado y mazizado segun buen arte demanera queno se le pase gota deagua, y hecho que sea y acavado dicho paredon en la conformidad arriba dicho se fabricara la casa deel molino en el paraxe queoy esta elixido poniendo o quitando loque fuere nezesario en las partes, que conbenga con declarazion, que la peña queesta por la parte de abaxo dedicha casa se ha de romper, paraque el expediente del agua benga mas corriente, quitandola dealli toda ella, y dicha casa de molino los tres astiales han deser depared y decal y canto, por la parte de abaxo seha deechar una viga de un pie de grueso que baia enbutida en los frontales de los astiales de dicha casa y sobre ella se fabricara el tavique arriba dicho dejando enelmedio una ventana quede luz y sobre dicha viga seasentaran las vigetas dell suelo de dicho molino, que tengan el gruesso y largo nezesario para su perpetuidad, y sobre ellas se tillara con tablas de roble bien juntadas, y dicha casa se cubrira segun arte echandole los cabrios, lata, y teja nezesarios de manera que dicha casilla y molino hade quedar fabricado entoda perfezion quedando acargo de dichas personas que le tomaren desu quenta todo lo que fuere nezesario como es el rodete nuebo sus manillas, y verros, soleras, sobre que se ha de asentar dicho rodete de manera que para toda la fabrica de dicho molino asi deel paredon, como de dicha casa y sus materiales ha decorrer por quenta de dichas personas sinque el dueño de dicho molino tenga obligazion adar cosa alguna, mas que la cantidad demoneda en que se ajustare, y la mitad dela cal que llevare dicha fabrica, y las ruedas de dicho molino, y todo lo demas que fuere necesario para darle usual, corriente y moliente, con llave en mano ha decorrer por quenta de dichas personas y la puerta de dicho molino ha deser de piedra labrado, y asi mismo es condizion que seha de labrar la coluna con basa y capitel y asentarla debaxo delas vigas frontales de la casa de dicho Dn Manuel de Zevallos y acavar la puerta que ba ala quenta echandosu cavallete en correspondencia delo demas. 


\section{MOLINOS DE RÍO EN LA LOCALIDAD DE CASTILLO SIETE VILLAS}

Castillo Siete Villas se ubica en el municipio de Arnuero, perteneciente a la antigua comarca de la Merindad de Trasmiera. A pesar de distar tan sólo $3 \mathrm{~km}$. en línea recta de la costa, conjunto de marismas de Victoria y Joyel, en el Antiguo Régimen su actividad productiva se basaba en el sector agrario, con una economía de mera subsistencia y prácticamente autárquica. Antes de la implantación del cultivo del maíz, las necesidades de productos panificables se cubrían, de manera harto insuficiente, con muy escaso trigo, el fruto del castaño y el mijo, "borona" ${ }^{35}$, pero a partir de fines del xvi el maíz va ocupando de manera creciente grandes espacios a costa de los anteriores y de nuevos territorios ganados al monte, “cierros. Sin duda, este panorama obligó a ampliar los molinos hidráulicos preexistentes, si no a construirlos de nueva planta.

Castillo Siete Villas no dispone de cursos de agua de importancia. De entre los existentes, sólo destaca el arroyo de Zoña, que presenta un sinuoso trazado y desemboca al fin en las marismas citadas. Esta dificultad se solucionaría con la construcción de cuatro molinos hidráulicos a lo largo del mismo curso fluvial, constituyendo un interesante caso de aprovechamiento extremo de los recursos hídricos (fig. 3). Añadamos que la estribación montañosa que separa a la localidad de la de Noja recibe el nombre de Sierra del Molino de Viento, quizá en referencia a uno de estos ingenios, que complementaría la labor de los anteriores y del que no conocemos vestigios materiales.

\subsection{MOLINO DE CORINO}

Este molino toma su nombre del afluente del arroyo de Zoña que discurre por la zona y del que tomaba sus aguas para la molienda. Se emplaza al pie de la Sierra Baranda, una gran masa caliza de $205 \mathrm{~m}$. de altitud máxima que marca los límites con los municipios de Meruelo y Escalante.

El molino se encuentra prácticamente desaparecido a causa de la reutilización de la mayoría de sus piedras para viviendas, cuadras, vallas de prados, etc.; sin embargo, el trazado de su represa aún se puede preci-

35 Las más antiguas ordenanzas concejiles de Castillo conocidas citan expresamente ambos productos, pero no recogen la existencia de molinos: E. SAN Miguel PÉrEz, La producción del derecho local en Trasmiera. El Concejo de Castillo y las Ordenanzas de 1531 (Santander, 1993), p. 64. 


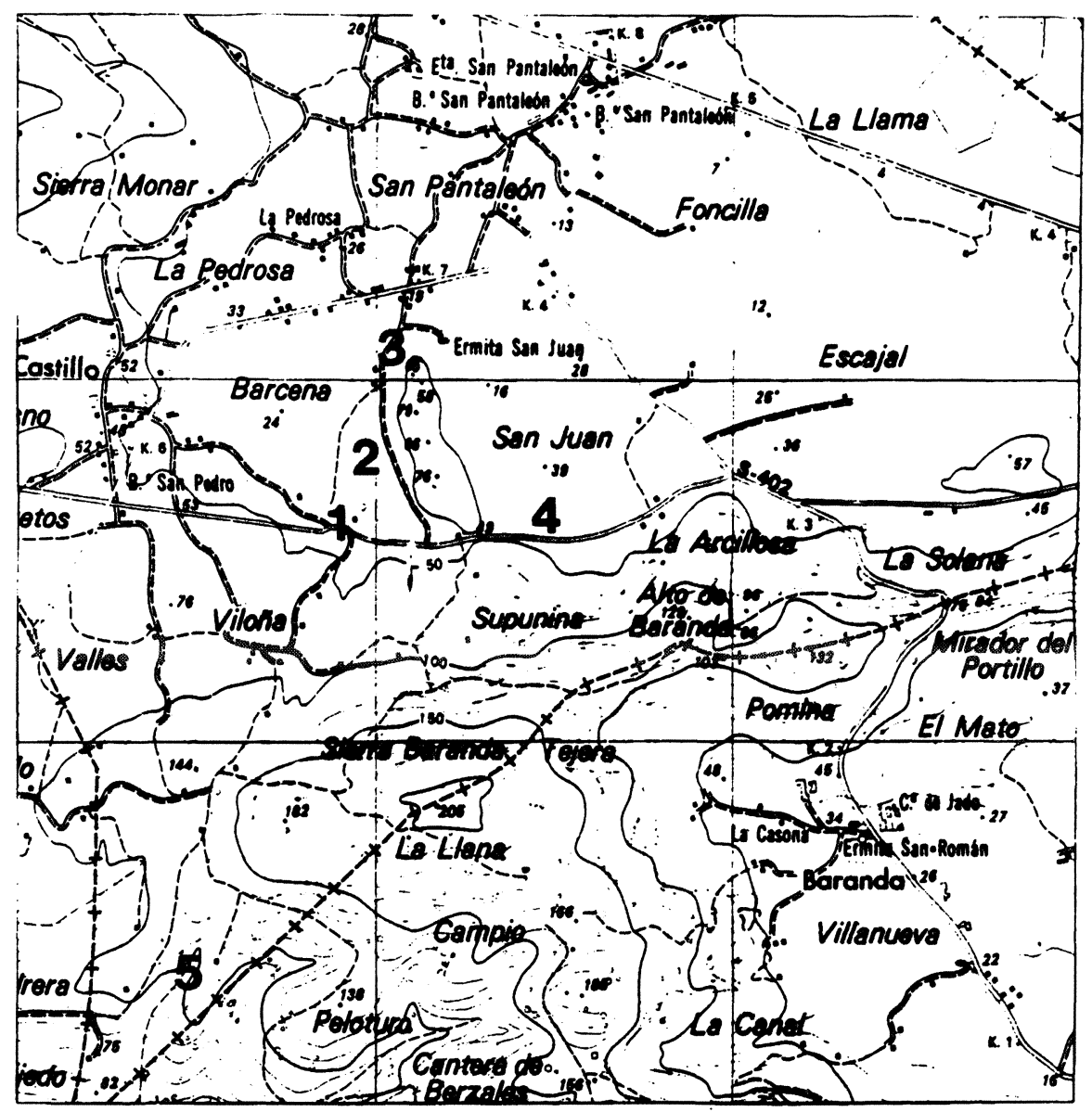

Figura 3.-Mapa de localización del arroyo de Zoña y sus molinos, en Castillo Siete Villas: 1.- Molino de Corino. 2.- Molino de Zoña. 3.- Molino de Puente. 4.- Molino de Candás. 5.- Molino de Los Vados.

sar, al permanecer excavada en el terreno, con una superficie cercana a los $20 \mathrm{~m}^{2}$. No se aprecia la existencia de revestimiento de mampostería en las paredes, y como rasgo distintivo señalemos que la escasa superficie se compensaba con una mayor capacidad, ya que, aprovechando la orografía del terreno, su profundidad era mayor de la habitual, 1,8 m., lo que proporciona unas reservas máximas cercanas a los $36 \mathrm{~m}^{3}$.

Gracias a las inquisitorias realizadas por orden del Marqués de la Ensenada a mediados del XvIII, sabemos que el Molino de Corino pertenecía a Don Andrés Antonio de Venero y Leyva, cuya torre solariega aún se alza a $100 \mathrm{~m}$. de distancia. Era éste "de una rueda que solo muele un mes al año en las crecidas lluvias del invierno"; el propietario gestionaba 
directamente su funcionamiento, valorándose si se arrendara "de renta anual a ocho reales y le quedara al rentero otra tanta cantidad" ${ }^{36}$.

\subsection{MOLINO DE ZOÑA}

En esta vega se ubican tres molinos más, el primero de los cuales está situado a unos $300 \mathrm{~m}$. del de Corino; su estado de conservación es en general deficiente, aunque mantiene la represa con muros de mampostería, con una superficie de $64 \mathrm{~m}^{2}$. El cuerpo del molino tiene unas dimensiones de $6 \mathrm{~m}$. de largo y $5,5 \mathrm{~m}$. de ancho, conservándose lienzos de sus muros hasta una altura máxima de $3,85 \mathrm{~m}$. Aún se aprecia el sistema de conducción y distribución de las aguas, con los huecos para la compuerta, de madera. A escasos metros de esta estructura se levantan las ruinas de otra edificación, según los lugareños ula casa de la molineran, muy probablemente relacionada con la actividad de la molienda ${ }^{37}$.

En 1753, el molino de Zoña "muele dos meses al año por lo común en el invierno". Era de una rueda, y su propiedad se la repartían cuatro vecinos en la proporción siguiente: "es propio la tercera parte de dicho Don José de Alvear, otra de Francisco del Solar y las tres partes de la otra de José de Zubieta y la cuarta de José del Solar vecinos de este lugar el que administran por sí y arrendado pudiera valer en cada año diez y seis reales de venta y quedarle de útil al rentero otros diez y seis reales" ${ }^{38}$.

\subsection{MOLINO DE PUENTE}

De este molino también ha desaparecido todo rastro de construcción, si bien se pueden apreciar los límites de su represa en el prado actual, con una superficie cercana a los $35 \mathrm{~m}^{2}$. Como el de Corino, era propiedad en el siglo xviII de la casa de Venero, poseía una rueda y también se podía utilizar únicamente un mes al año ${ }^{39}$.

36 T. MAZA SOLANO, Relaciones histórico-geográficas y económicas del Partido de Laredo en el siglo XVIII (Santander, 1972), tomo 3, p. 302.

$37 \quad$ En uno de sus muros se encuentra una ventana rectangular labrada en un solo bloque de arenisca, abocinada por sus dos caras y apoyada en la pared por su eje mayor. Probablemente estemos ante un ejemplo de reutilización de un elemento constructivo anterior a este edificio.

38 T. MAZA SOlano, op. cit., n. 36, p. 303.

39 ...y otro en el sitio de Puente, sobre el arroyo de Zoña...: T. MAZA SOLANO, op. cit., n. 36 , p. 302 . 


\subsection{MOLINO DE CANDÁS}

Esta aceña está situada cerca de $1.200 \mathrm{~m}$. al Este de los anteriores, sobre el mismo arroyo de Zoña, que cerca de ese punto cambia su orientación hacia el Norte, atravesando la zona de Las Llamas hasta desembocar en las marismas de Rota-Fonegra.

Su estado de conservación era aceptable hasta hace cerca de diez años, en que se construyó encima una cuadra. Sin embargo, aún pervive la parte de conducción del agua, a base de grandes sillares bien escuadrados. La represa, de muros terreros, posee una superficie cercana a los $46 \mathrm{~m}^{2}$.

El molino de Candás pertenecía en 1753 a dos labradores vecinos de Castillo Siete Villas, Pedro de la Sierra y Francisco de Arnuero, "quienes por sí le administran y arrendado consideran podía valer de renta anual veinticuatro reales y que le quedaran al arrendatario otros veinticuatro"; poseía dos ruedas, "que la una muele por lo regular dos meses y la otra uno al año en el invierno cargado de aguas" ${ }^{40}$.

\subsection{MOLINO DE LOS VADOS}

Este molino se ubica al Sur de la localidad, al final del "pico" que se interna en los municipios de Meruelo y Escalante. Aprovecha las aguas del arroyo de Los Vados en una zona de brañas y multitud de pequeños riachuelos procedentes de la Sierra Baranda.

En la actualidad el arroyo no sigue su trazado original, ya que discurre por el borde de la represa del molino. De la aceña, muy expoliada por el empleo de sus piedras en vallas para prados, sólo se conservan las primeras hiladas del sistema de captación y conducción del agua, en sillares. No se menciona en el Catastro del Marqués de la Ensenada.

\section{MOLINOS DE MAREA EN LA RÍA DE LIMPIAS ${ }^{41}$}

En la zona oriental de Cantabria, en el Bajo Asón, dos rías de pequeño tamaño, la de Limpias y la de Rada, se funden en las cercanías de

\section{Ibidem}

¿1 El trabajo de campo se ha centrado en el municipio de Colindres y sólo se recogen los molinos de marea cuya ubicación es colindante con áquel término municipal y que están situados dentro de las coordenadas geográficas para las que se tenían los pertinentes permisos de prospección y documentación. Esta labor de campo se 
Treto-Colindres, pasando a denominarse Ría de Treto. A través de ella las aguas de los ríos Asón y Clarín alcanzan el mar en la Bahía de Santoña. Nos encontramos ante un marco geográfico litoral estructurado en rías, bahía y zonas de inundación mareal, que forma parte de la Reserva Natural de las Marismas de Santoña.

A la ría de Treto-Colindres afluye el Asón, por la ría de Limpias, y el Clarín - al que previamente se ha unido el Clarón-, por la de Rada. Respecto al primero de estos cursos de agua, el Asón, su cuenca de drenaje se extiende sobre $562 \mathrm{~km}^{2}$ y su caudal medio anual puede situarse en torno a los $45 \mathrm{hm}^{3}$ en su desembocadura ${ }^{42}$.

La ría presenta unas características interesantes en lo que respecta al emplazamiento de molinos de marea. La acumulación de limos y arcillas a ambas márgenes contribuyó a la formación de ensenadas, esto es, lugares que solamente recibían agua con efecto de la pleamar, quedando prácticamente secas en la bajamar. De hecho, la amplitud media de la marea se sitúa en torno a los $35 \mathrm{~m}$. y la influencia del mar en la ría de Limpias se deja notar incluso en las proximidades de Ampuero ${ }^{43}$.

Los molinos documentados se encuentran en la margen derecha de la ría de Limpias: dos, en el municipio de Colindres, y uno en el municipio de Limpias; a ellos hay que unir un cuarto molino situado en un islote formado en el interior de la ría, perteneciente al municipio del mismo nombre. Conviene señalar que las acciones humanas sobre estas zonas tienden a ser agresivas. Los vertidos incontrolados no solo suponen una alteración del medio, sino que en muchos casos están condenando a este Patrimonio a una muerte prematura (fig. 4).

\subsection{MOLINOS DE MAREA DEL MUNICIPIO DE COLINDRES}

Aunque solamente nos ceñiremos al municipio de Colindres, conviene señalar la existencia de estructuras de este tipo en la otra margen de la ría de Limpias y en la de Rada. Así, algunos documentos sugieren su existencia en los lugares de Carasa:

efectuó durante 1993 y 1994. En el primero de estos años dentro de la "Prospección arqueológica del Astillero de Colindres", dirigida por M. Cisneros Cunchillos y en el segundo de ellos, dentro de la "Documentación de estructuras hidráulicas y defensivas del Astillero de Colindres", dirigida por M.Cisneros Cunchillos y R. Palacio Ramos. El equipo de investigación, además, estuvo formado por P. Chaves Castanedo, P. López Noriega, R. Madrazo Fernández y M. J. Pérez Cotta.

42 VV.AA., La reserva natural de Santoña, Victoria y Joyel, 1993, p. 41.

43 VV.AA., op. cit., n. 42, pp 41 y 48. 


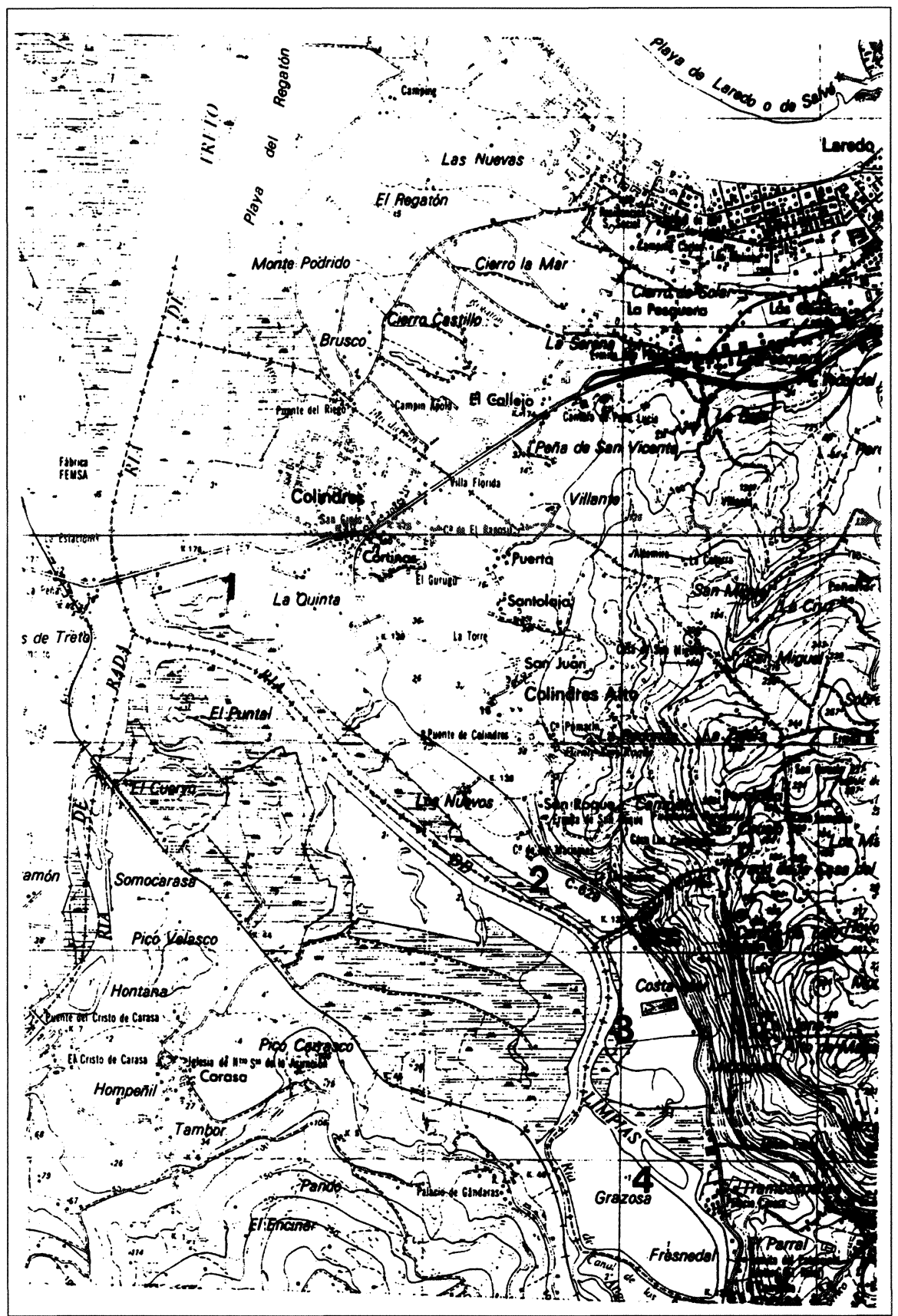

Figura 4.-Mapa de localización de los molinos de la ría de Limpias: 1 . Molino de la antigua Calle del Mar (Colindres). 2. Molino Viejo de Los Nuevos (Colindres). 3. Molino de Los Nuevos o de Angulo (Limpias). 4. Molino de La Grazosa (Limpias). 
dijeron que en este lugar hay diferentes molinos de agua salada que solamente muelen en las mareas vivas que son 50 días al año, y regulan el producto de cada uno de ellos a prudente regulación consideran de cada rueda la utilidad de 6 fanegas de maíz en cada año por ser la especie que muelen solamente ${ }^{* 4}$ y de Rada: hay tres casas de molino en cuyas tres casas hay siete ruedas y el producto de cada rueda la regulan en diez fanegas de maíz al año ${ }^{45}$.

En cuanto a Colindres, desde hace décadas era conocida la existencia de molinos de marea en este término municipal; de hecho, M. ${ }^{a}$ C. González Echegaray, además de los citados en el apartado 3, menciona uno en Jergote, otro en la Cuesta de San Juan, los de Arredondo y el de los Nuevos de Angulo, muy próximo a Limpias ${ }^{46}$. P. Madoz menciona, a mediados del siglo XIX, la existencia de tres molinos harineros en Colindres y, en cuanto a Limpias, refiere " 3 molinos harineros que sólo muelen una tercera parte del año con las aguas del Asón, y otros dos de pleamar en la ría" ${ }^{47}$. Sin embargo, hasta la actualidad, no se había procedido a su comprobación y localización, ya que los estudios sobre el tema en Cantabria han incidido en la Ría de La Venera, en la de Quejo, en la marisma del Joyel, en la de Victoria y en las Siete Villas ${ }^{48}$.

\subsection{MOLINO DE LA ANTIGUA CALlE DEL MAR}

Su denominación procede de los datos que se poseen del Registro de la Propiedad de Laredo ${ }^{49}$. Ubicado junto a un polígono industrial, su orientación es Nordeste-Suroeste y es colindante a la marisma.

El molino es una estructura hidráulica que consta de un dique de contención y desviación del agua, durante las pleamares, de tamaño sin especificar, debido a la gran cantidad de maleza que lo cubre, y de un

44 T. MAZA SOlano, op. cit., n. 36, p. 346.

45 T. Maza SOlano, op. cit., n. 36, p. 351.

46 M." C. González Echegaray, op. cit., n. 28, pp. 91-94 y P. Madoz, Diccionario Geográfico-Estadístico-Histórico de España y sus posesiones de Ultramar. 1845-1850, Santander (Santander, 1984), fig. s/p, sitúa el de Arredondo y el de los Nuevos de Angulo.

47 P. MADOZ, op. cit., n. 46, pp. 92 y 137.

48 L. AZurmendi, op. cit., n. 15 y op. cit., n. 18, y L. De escallada GonZÁlez, op. cit., n. 18.

49 Laredo. Registro de la Propiedad. Tomo 118. Folio 200. Finca n. 741 . Agradecemos a D. J. R. Cornejo la amabilidad que tuvo al poner a disposición del proyecto "El Astillero de Colindres: recuperación arqueológica y documental de su actividad", citado en la n. 1, algunas de las fotocopias que poseía realizadas en el mencionado Registro. 
arco de ladrillo, así como de la base de la edificación en la que se insertaba. Sus dimensiones actuales son de 8'10 m. de largo y 3'35 de ancho, siendo la luz del arco de 1'80 m. (figs. 5 y 6). La edificación conserva, en parte, sillares de su estructura, y en las esquinas, así como hiladas que en la actualidad están a nivel del agua.

Su estado de conservación es lamentable (fig. 7). Actualmente, es usado como basurero por parte de los diversos talleres del polígono industrial. Su estado de deterioro en los últimos años se ha acentuado, dado que, además, ha sido parcialmente destruido u ocultado por una vía de

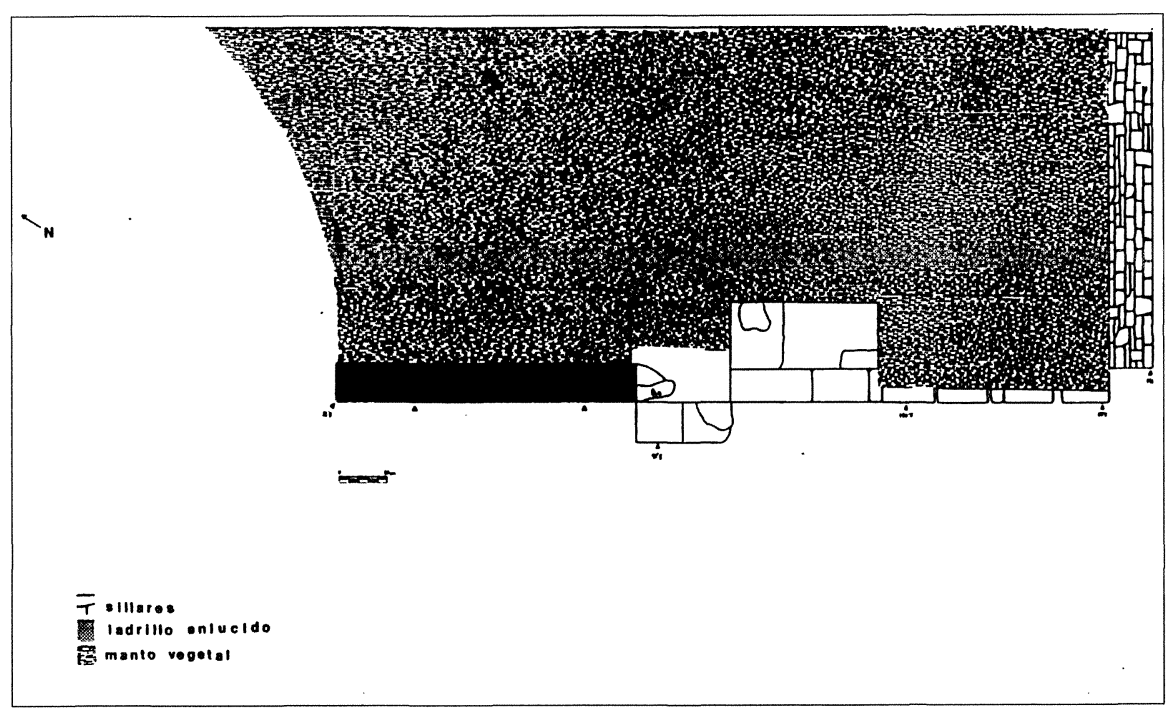

Figura 5.-Molino de la antigua Calle del Mar (Colindres). Planta.

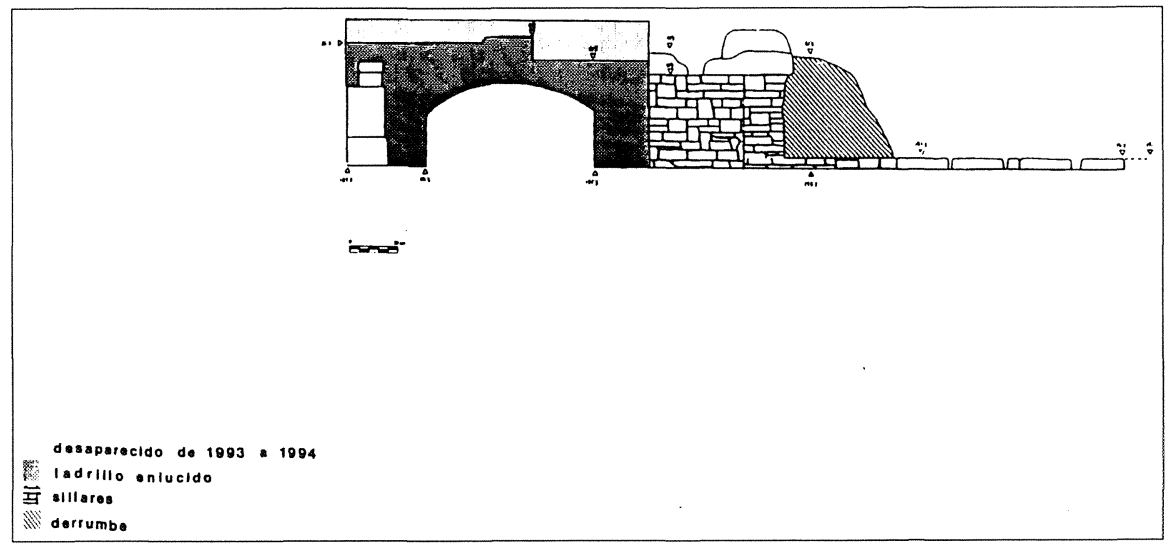

Figura 6.-Molino de la antigua Calle del Mar (Colindres). Sección. 


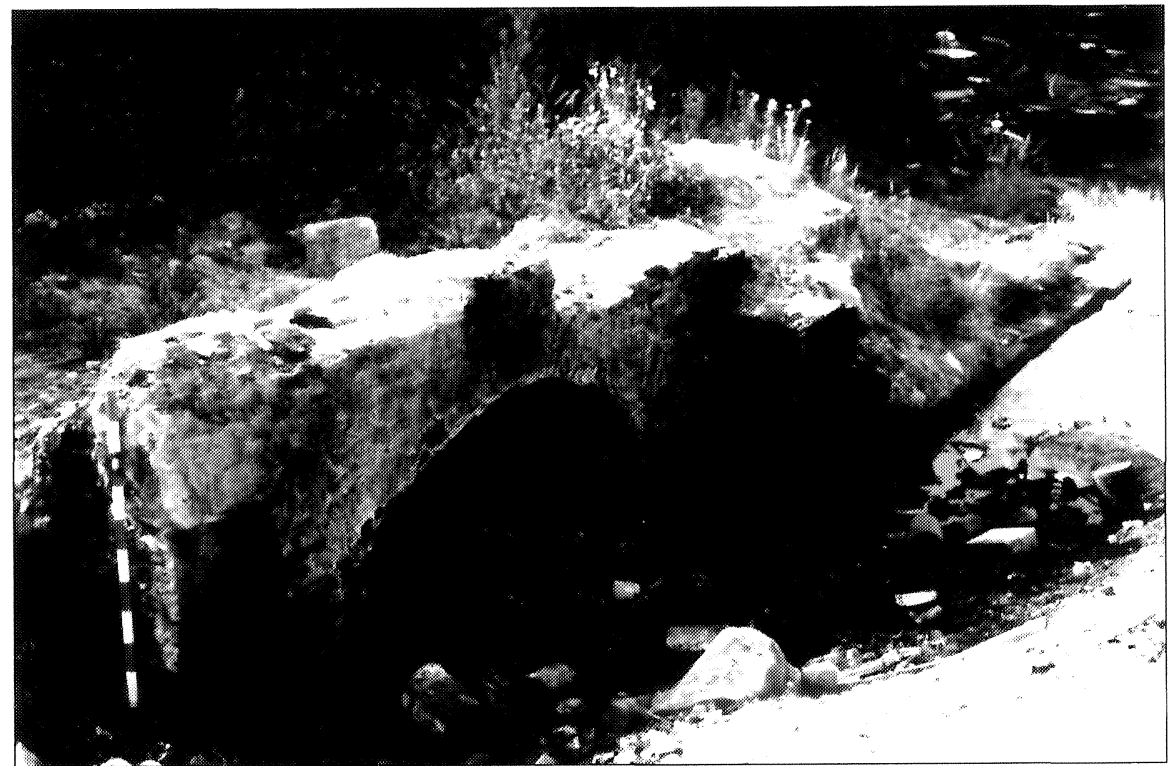

Figura 7.-Arcada y sillares a nivel de agua del Molino de la antigua Calle del Mar (Colindres).

servicio de la Autovía del Cantábrico, que, por diversos problemas ajenos a este molino, se ha encontrado detenida durante varios años; por todo ello es presumible que en su origen pudiese tener mayor número de arcadas. Además, se halla inmerso dentro del plan de costas y de la reordenación de las marismas de la zona.

\subsection{Molino Viejo de los Nuevos}

Su nombre procede de la referencia existente en el mapa publicado por la Dirección General del Instituto Geográfico Nacional en 1926-1927, donde se especifica que en esta fecha estaba en desuso. Su orientación es Nordeste - Suroeste y se encuentra colindante a la ría de Limpias, junto a una zona de pastos. Es una edificación de la que se conserva la primera planta del molino, propiamente dicho, y el dique de retención de agua.

La fábrica del molino, de planta rectangular, tiene $6,20 \mathrm{~m}$. de longitud y 8 de anchura. La altura de lo conservado oscila entre 3,60 y 4,20 m. (figs. 8 y 9). En su lado Oeste, que da a la ría, presenta un arco, en la actualidad cegado (fig. 10), y en el Este, dos vanos adintelados. A través de ellos pasaría el agua, generando la fuerza motriz. La estructura fue 


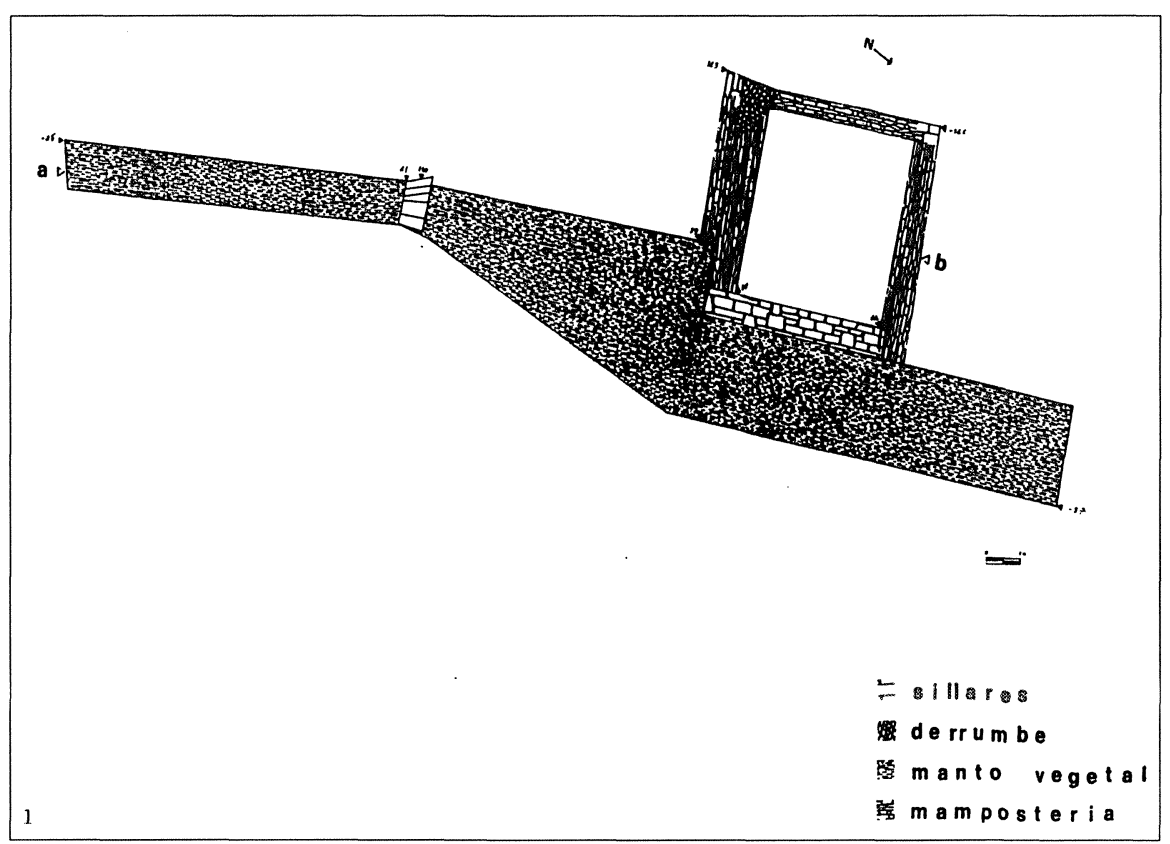

Figura 8.-Molino Viejo de Los Nuevos (Colindres). Planta.

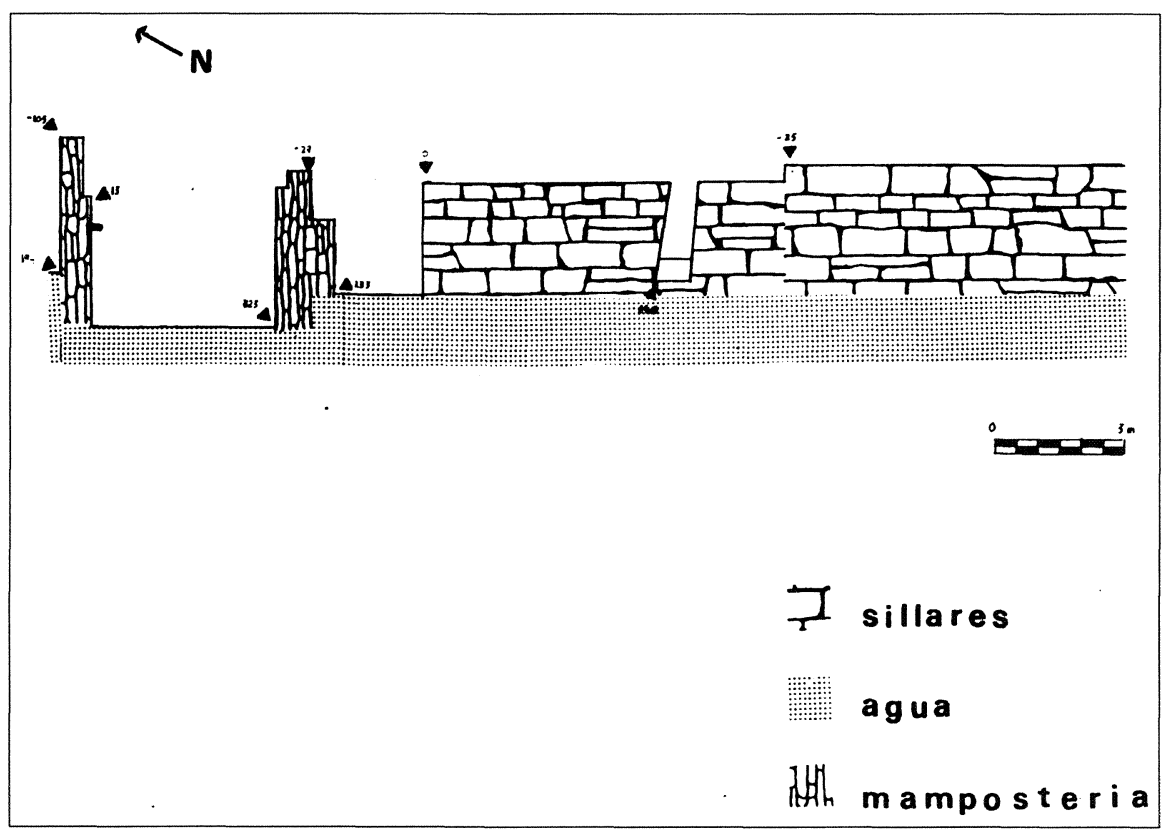

Figura 9.-Molino Viejo de Los Nuevos (Colindres). Sección. 


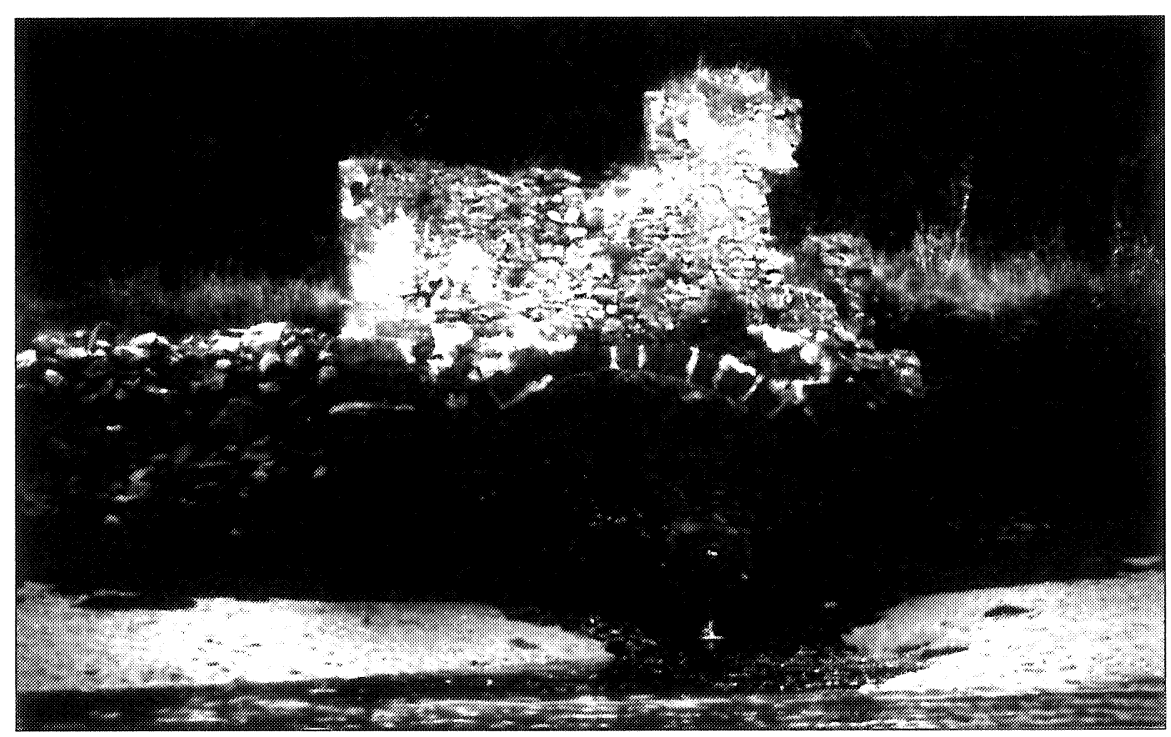

Figura 10.- Vista del Molino Viejo de Los Nuevos (Colindres) desde la ría de Limpias.

realizada con mampuestos irregulares, reservando el uso de sillares para las esquinas de la estructura, el arco y el lado Este. Los restos de una ventana en la zona superior del muro Oeste son el único indicio que se conserva de la existencia de un segundo piso.

El dique, realizado con sillares, cuenta con una escalera de acceso a la ría de $70 \mathrm{~cm}$. de anchura. Tiene unos $49 \mathrm{~m}$. de largo, una altura de 2,50 y su anchura de $1,10 \mathrm{~m}$. va aumentando progresivamente, según se aproxima a la estructura del molino, hasta alcanzar aquí los 4,25 m.

Su estado de conservación es deficiente, dado que el piso que se conserva presenta derrumbe de muro en el Suroeste, haciendo prever la desaparición paulatina de la pared y del edificio.

\subsection{MOLINOS DE MAREA DEL MUNICIPIO DE LIMPIAS}

\subsubsection{Molino de los Nuevos o de Angulo}

A pesar de su actual inclusión en el término municipal de Limpias, se trata del que tradicionalmente se ha situado en el de Colindres, no ofreciendo dudas su denominación por las referencias que suministra el mapa de P. Madoz ${ }^{50}$. Ubicado en el paraje de Costa-Mar, su orientación es Su-

\footnotetext{
50 P. MADOZ, op. cit., n. 46, fig. s.p.
} 
roeste - Nordeste y se encuentra colindante a la ría de Limpias, en un entorno de pastos, junqueras, marisma y ría. Es una estructura formada por el molino propiamente dicho, y por un dique de contención de las aguas.

La estructura del molino, configurado por sillares en sus lados Norte, Este, Oeste y parte inferior Sur, presenta cinco arcos de construcción y luces variables, dadas las diferentes reconstrucciones de las que ha sido objeto, debido al deterioro que se desprende de su uso y del empuje de las aguas con la pleamar. La estructura tiene $20,22 \mathrm{~m}$. de longitud, 4 de anchura y la altura de lo conservado oscila entre 1,90 y $2,90 \mathrm{~m}$. Al Oeste quedan los restos de lo que en su momento fue una escalera de acceso a la ría, hoy derruida, y un pozo, de planta rectangular, de algo más de $2,50 \mathrm{~m}$. de profundidad (figs. 11 y 12). El dique de contención de las aguas, de mampostería, presenta $41 \mathrm{~m}$. de longitud, de 1,50 a 4,50 m. de anchura y de 2 a $2,90 \mathrm{~m}$. de altura.

Está deteriorado por el abandono y por el empuje constante de las aguas, ya que se ubica en un recodo de la Ría de Limpias, lo que origina constante presiones en las pleamares y bajamares.

\subsubsection{Molino de la Grazosa}

Denominado así por ubicarse en el paraje llamado de La Grazosa. Desde Limpias, para acceder a él, es necesario tomar una barca, puesto

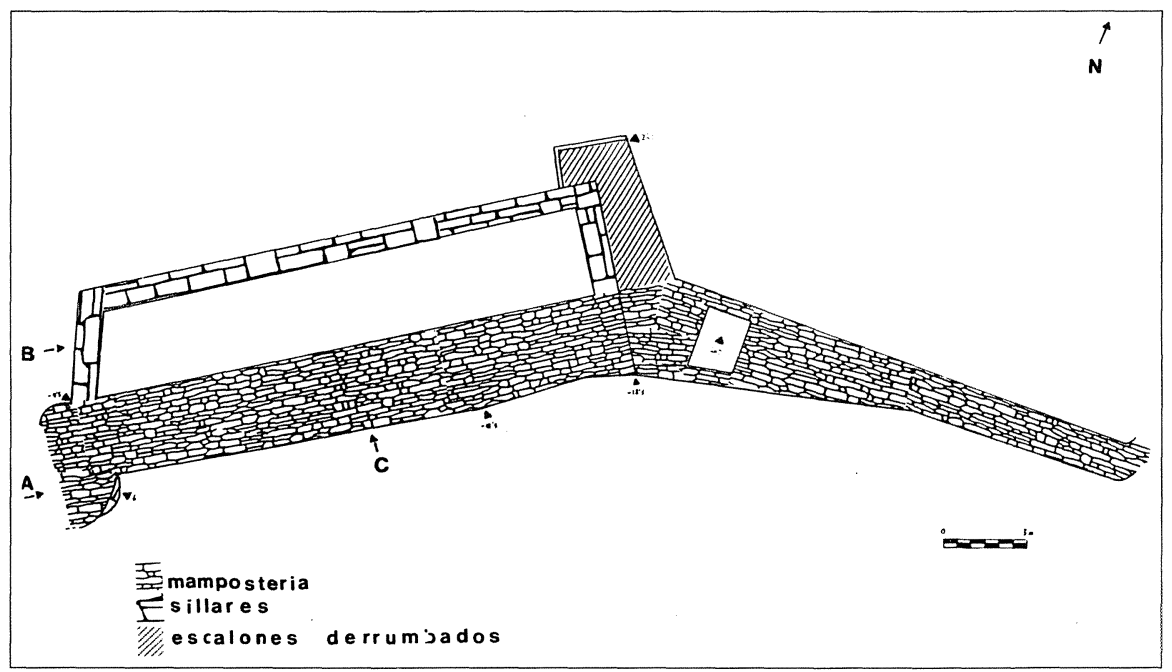

Figura 11.-Molino de Los Nuevos o de Angulo (Limpias). Planta. 


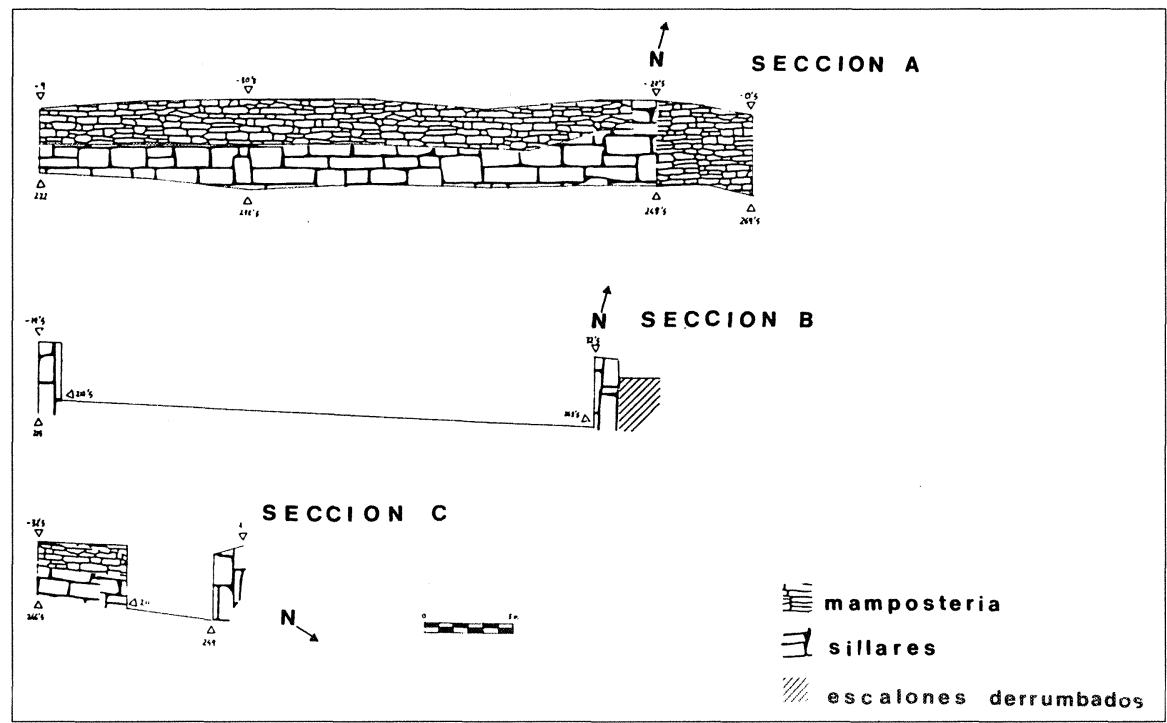

Figura 12.-Molino de Los Nuevos o de Angulo (Limpias). Sección.

que se halla en medio de la ría. Situado en un entorno de junqueras, el molino consta de tres arcos y un vano adintelado, de sillares en la parte inferior y mampostería en la superior. Se conserva el basamento y un primer piso, quizá la vivienda (fig. 13).

Respecto a su estado de conservación, está deteriorado por el empuje de las aguas, aunque por su aislamiento, en medio de la ría, se ha mantenido al margen de la acción antrópica.

\section{CONCLUSIONES}

Los molinos hidráulicos desempeñaron una importante función económica durante la época moderna en Cantabria, pero en el momento en que se produjo su declive, por las causas ya comentadas en el apartado 2, debió comenzar un lento y paulatino abandono; algunas de estas estructuras se utilizaron con otros fines, así, hasta hace pocas fechas, y en algunos casos todavía en la actualidad, los diques de los de marea sirvieron para la pesca y el atraque de pequeñas embarcaciones y con el cierre permanente de lo que un día fue el embalse se han ganado tierras, convertidas en pastizales. Pero, en nuestros días, en la Comunidad Autónoma de Cantabria este Patrimonio se encuentra en un patente estado de abandono. El presente trabajo sólo ha pretendido documentar una serie de molinos de río y de marea, llamar la atención sobre estas estructuras, 


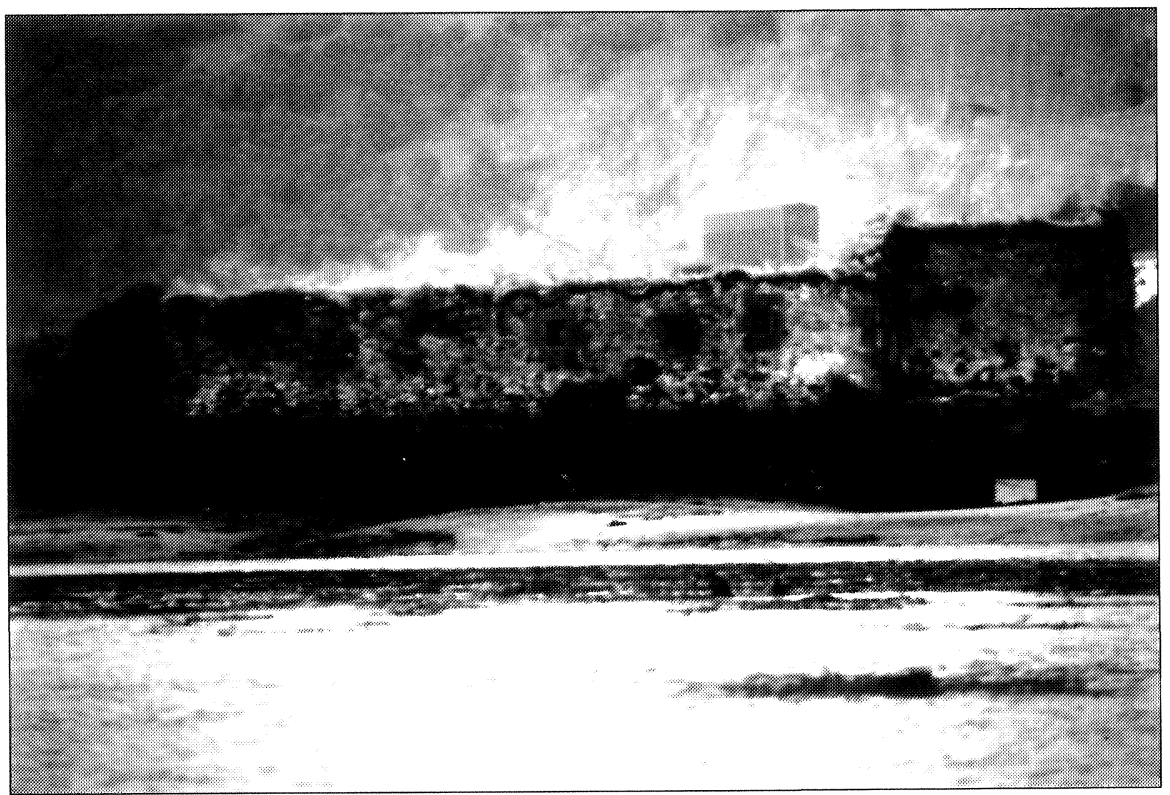

Figura 13.-Vista del Molino de La Grazosa (Limpias) desde la ría de Limpias.

frecuentes en la cornisa cantábrica y continuar una línea de trabajo ya iniciada por otros investigadores, con objeto de tener una información lo más completa posible de estas estructuras, que han dejado su huella arqueológica a través de los años, pero que por la acción antrópica, por la acción de las mareas o por el abandono del que han sido objeto pueden desaparecer en breve, como ya se ha señalado para el molino de marea de la antigua Calle del Mar, en Colindres, y los molinos de río de Zoña y Candás, en Castillo Siete Villas; localidad ésta en la que otras tres aceñas, las de Corino, Puente y Los Vados, sólo son reconocibles gracias a la tradición oral y a los escasísimos restos materiales que la acción antrópica ha dejado in situ. 
El artículo estudia los molinos de río de Castillo Siete Villas y los de marea de Colindres y Limpias, municipios situados en la Cantabria Oriental, como ejemplo del aprovechamiento exhaustivo de los recursos naturales de estas áreas en época moderna, ofreciendo su relación, enmarcándolos en su contexto histórico, aportando documentación inédita procedente de los archivos y llamando la atención sobre su estado de conservación, muy deteriorado por la acción antrópica, fundamentalmente, pero también por la de las mareas y, en general, por el abandono del que han sido objeto.

The authors describes the river mills of Castillo Siete Villas and the tide mills of Colindres and Limpias, in eastern Cantabria. These mills exemplify the exhaustive use of natural resources in the region in the Modern period. The authors reconstructs from archival sources the connections among the mills and the historical context of their use. They calls attention to their state of preservation, which is poor, because of human action and the constant ebb and flow of the tide; the mills have been neglected for a long time. 